Article

www.mdpi.com/journal/polymers

\title{
Laccase Functionalization of Flax and Coconut Fibers
}

\section{Enrique Herrero Acero ${ }^{1}{ }^{*}$, Tukayi Kudanga ${ }^{2}$, Andreas Ortner ${ }^{1}$, Iwona Kaluzna ${ }^{3}$, Stefaan de Wildeman ${ }^{3,4}$, Gibson S. Nyanhongo ${ }^{5}$ and Georg M. Guebitz ${ }^{1,5}$}

1 Enzymes \& Polymers, Austrian Centre of Industrial Biotechnology, Konrad Lorenz Strasse 20, 3430 Tulln, Austria; E-Mails: andreas.ortner@acib.at (A.O.); georg.guebitz@acib.at (G.M.G.)

2 Biocatalysis and Technical Biology Research Group, Cape Peninsula University of Technology, Bellville Campus, PO Box 1906, Bellville 7535, South Africa; E-Mail: kudangat@cput.ac.za

3 DSM Innovative Synthesis B.V., Urmonderbaan 22, 6167 RD Geleen, P.O., 6160 MD Geleen, The Netherlands; E-Mails: iwona.kaluzna@dsm.com (I.K.); s.dewildeman@maastrichtuniversity.nl (S.W.)

4 Aachen-Maastrich Institute for Biobased Materials, Maastricht University, PO Box 616, 6200 MD Maastricht, The Netherlands

5 Institute for Environmental Biotechnology, University of Natural Resources and Applied Life Sciences, Vienna, Konrad Lorenz Strasse 20, 3430 Tulln, Austria; E-Mail: g.nyanhongo@ boku.ac.at

* Author to whom correspondence should be addressed; E-Mail: enrique.herreroacero@acib.at.

Received: 25 March 2014; in revised form: 20 May 2014 / Accepted: 26 May 2014 /

Published: 30 May 2014

\begin{abstract}
Natural fibers have gained much attention as reinforcing components in composite materials. Despite several interesting characteristics like low cost, low density, high specific properties and biodegradability they show poor compatibility with the polymer matrix. We have shown that it is possible to use a laccase from Trametes hirsuta as a biocatalyst to attach different types of functional phenolic molecules onto the fibers. A $5 \%$ incorporation of the functional molecules was achieved as measured via X-ray photoelectron spectroscopy (XPS) in flax although it was lower in coconut fibers. In combination with different mediators it was possible to broaden the activation scope and graft hydrophobic molecules like dimer fatty amines. Among the different mediators tested 1-hydroxybenzotriazole (HBT), 2,2,6,6-tetramethylpiperidin-1-yloxy (TEMPO) and 2'-azino-bis(3-ethylbenzothiazoline-6-sulphonic acid) (ABTS), TEMPO were the most effective achieving a $10 \%$ increase in carbon as measured by XPS.
\end{abstract}


Keywords: laccase; flax; coconut; dimer fatty amine

\section{Introduction}

Laccases (E.C.10.3.2), p-diphenol dioxygen oxidorecductases, are multi-copper containing enzymes performing a one-electron oxidation of many structurally different aromatic substrates while simultaneously reducing oxygen to water. This family of enzymes has found numerous applications in diverse fields like environmental pollution control [1], organic synthesis [2,3] and several industrial areas like pharmaceutical [4,5], food [6,7], textile [8,9], etc.

The reaction catalyzed by laccases generates highly reactive radicals, which makes it difficult to control the process and an accurate prediction of the final reaction products. However, laccases have been successfully used to functionalize complex substrates, turning their high unspecifcity into a benefit as well as upgrading the properties of pulp.

For example, bio-bleaching of pulp with different laccase has been successfully achieved [10,11]. Laccase mediated grafting of different types of phenols is a common strategy $[12,13]$ that can be used to introduce new properties onto cellulosic fibers, e.g., conferring antibacterial properties [14], increasing the pulp strength and swelling properties [15]. In addition to modification of pulp properties, laccases have also been successfully used to improve the hydrophobicity of wood veneers by grafting fluorophenols [16] or alkylamines [17].

There is a huge potential for the production of novel materials through combining natural fibers with synthetic materials for the production of composites materials, with excellent properties. However, incompatibility issues with common materials like synthetic polymers [18] hinder a wider application. For example, the introduction of a hydrophilic material into a highly hydrophobic matrix as synthetic polymers, typically leads to a material with poor properties, due to the low adhesion between the fiber and the matrix. Depending on the nature of the fiber different chemical treatments followed by graft polymerization can be a suitable approach to improve the matrix-fiber interaction. There are several commercial coupling agents with different reactive chemistry like silane, isocianate, titanate or zirconate which can include a high variety of moieties into the fiber like vinyl, chloropropyl, epoxy, methacryl, amine, mecarpto, phosphate [18].

In this paper we show the effectiveness of two different approaches for the functionalization of coconut and flax fibers using laccase as environmentally friendly catalyst to effectively substitute traditional toxic chemicals. In the first approach laccase is used to oxidize different phenols, creating reactive radicals that can couple via formation of new $\mathrm{C}-\mathrm{C}, \beta-\mathrm{O}-5$ or $\mathrm{C}-\mathrm{O}$ bonds to the fiber. In the second approach using the same enzyme and in combination with some mediators it was possible to oxidize the lignin parts of the fiber generating phenol radicals that can easily reacted with amines. The functional molecules used were chosen based on previous mechanistic studies, which showed the possibility of oxidizing these molecules and coupling them onto lignin model substrates [16,17]. The study shows that, based on the properties of the phenolic molecules or amines used for grafting, it is possible to achieve a wide range of functional materials in an environmentally friendly way. 


\section{Experimental Section}

Flax and coconut fibers were provided by DSM N.V. (Heerlen, The Netherlands), and the following dimer fatty amines (DFA) (Pripol ${ }^{\mathrm{TM}}$ 1740, Croda, The Netherlands) was used. The fluorophenols, 4-(trifluoromehtoxy)phenol (4-F3MP), 4-fluoro-2-methylphenol (4,2-FMP) and 4-[4-(trifluoromethyl)phenoxy]phenol (4,4-F3MPP) (Figure 1) and all other chemicals were purchased from Sigma Aldrich (St. Louis, MO, USA) and were of the highest grade available.

Figure 1. Structures of the fluorophenols used in the coupling reactions: (a) 4-F3MP; (b) 4,2-FMP; and (c) 4,4-F3MPP.<smiles>Oc1ccc(OC(F)(F)F)cc1</smiles>

(a)<smiles>Cc1cc(F)ccc1O</smiles>

(b)

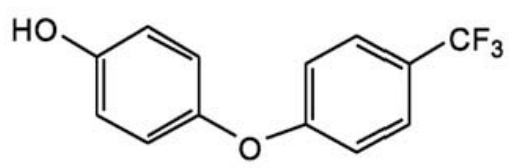

(c)

The laccase from Trametes hirsuta was produced and purified as previously described by Almansa et al. [8]. Laccase activity was determined spectrophotometrically by following the oxidation of, 2'-azino-bis(3-ethylbenzothiazoline-6-sulphonic acid (ABTS) at $420 \mathrm{~nm}\left(\varepsilon=36,000 \mathrm{M}^{-1} \mathrm{~cm}^{-1}\right)$ as described by Greimel et al. [19] with some modifications. The reaction mixture contained $650 \mu \mathrm{L}$ of enzyme diluted in $50 \mathrm{mM}$ succinate buffer, $\mathrm{pH} 4.5$ and $200 \mu \mathrm{L}$ of ABTS (10 mM in $50 \mathrm{mM}$ succinate buffer, $\mathrm{pH}$ 4.5). The absorbance was followed for $1 \mathrm{~min}$ in time scan mode with a spectrophotometer U-2001 (Hitachi, Tokyo, Japan). Enzyme activity is expressed in katal, whereas one katal (katal) is defined as the amount of enzyme that catalyzes the conversion of 1 mole of ABTS per second.

Direct and mediated functionalization of flax and coconut fibers was performed in $2 \mathrm{~mL}$ eppendorf tubes. In the case of the direct laccase fiber functionalization with the fluorophenols $15 \mathrm{mg}$ of the corresponding fiber were placed in the tube with the corresponding fluorophenol in a final concentration of $2.0 \mathrm{mM}$ with a final enzyme activity of $9 \mathrm{katal} / \mathrm{mL}$ in $50 \mathrm{mM}$ succinate buffer $\mathrm{pH} 4.5$ at $37{ }^{\circ} \mathrm{C}$ and $300 \mathrm{rpm}$ for $3 \mathrm{~h}$. The unbound fluorophenols were removed by washing with $75 \%$ ethanol for $16 \mathrm{~h}$.

In the case of mediated coupling reaction of water insoluble DFA, a stock solution of $6 \mathrm{~g} / \mathrm{L}$ in ethanol was produced; similarly a $20 \mathrm{mM}$ stock solution of the mediators ABTS, 1-hydroxybenzotriazole (HBT) and 2,2,6,6-tetramethylpiperidin-1-yloxy (TEMPO) in buffer (50 mM succinate buffer, $\mathrm{pH} 4.5$ ) was prepared.

The reaction was carried out in $2 \mathrm{~mL}$ eppendorf tubes with $15 \mathrm{mg}$ of fiber, $9 \mathrm{katal} / \mathrm{mL}$ of enzyme, $1 \mathrm{mM}$ of the corresponding mediator and $2.7 \mathrm{~g} / \mathrm{L}$ of the DFA. Incubation was carried out at $37{ }^{\circ} \mathrm{C}$, $3 \mathrm{~h}$ and $300 \mathrm{rpm}$ using a Thermomixer (Eppendorf, Hamburg, Germany). The unbound amines were removed by with ethanol for $16 \mathrm{~h}$.

The XPS measurements were carried out using a Quantera SXM X-Ray Photoelectron Spectrometer (XPS) from Ulvac-PHI (Q2) (Kanagawa, Japan). During the measurements the angle between the axis 
of the analyzer and the sample surface was approximately $45^{\circ}$; the information depth is then about $7 \mathrm{~nm}$. The measurements were performed using monochromatic AlK $\alpha$-radiation (100 Watt) and a measurement spot of $100 \mu \mathrm{m}$, scanned across an area of $1200 \mu \mathrm{m} \times 500 \mu \mathrm{m}$.

By means of wide-scan measurements the elements present at the surface were identified. Narrow-scan measurements have been performed to determine the concentrations and chemical binding states of the elements.

\section{Results and Discussion}

Oxidative enzymes have found wide applications in the field of polymer functionalization for different applications like personal care, textile industry, biosensors and organic synthesis [20].

In this study laccase oxidation of the lignin moieties present in coconut and flax had the goal of activating the lignin moieties present in the fibers, which in turn would allow covalent grafting of the functional fluorophenolic molecules. XPS analysis revealed the different reactivity of the flax and coconut fibers, which are most likely due to differences in their lignin content (Tables 1 and 2).

A slightly higher modification/incorporation of fluorophenols was achieved with flax fibers (Tables 1 and 2). Laccase oxidative coupling reactions involving different types of soluble molecules to lignin or lignin model substrates has previously been described for wood based materials [16,21]. In our previous mechanistic studies, the use of defined model substrates revealed that both 5-5 and 4-O-5 coupling reactions were possible [16,21-23] and this can be used to explain the couplings in this study.

Laccase activated functional molecules have not been only limited to lignocellulosic materials but also chitosan using different low molecular weight phenols like caffeic and gallic acid to improve the antioxidant and antimicrobial properties [24].

Similarly, laccases have been used to bleach pulps with leading to a decrease in residual lignin present in the pulp [25].

Table 1. XPS analysis of coconut fibers after laccase treatment with different fluorophenols.

\begin{tabular}{cccccc}
\hline Sample & \% C & $\mathbf{\%} \mathbf{F}$ & $\mathbf{\%} \mathbf{O}$ & $\mathbf{F} / \mathbf{C}$ & $\mathbf{O} / \mathbf{C}$ \\
\hline Flax + Laccase & 65.6 & - & 27.2 & - & 0.415 \\
Flax + Laccase + 4,2-FMP & 64.5 & - & 30.2 & - & 0.468 \\
Flax + Laccase + 4,-F3MP & 65.6 & 0.7 & 27.6 & 0.011 & 0.421 \\
Flax + Laccase + 4,4-F3MPP & 61.0 & 0.5 & 31.3 & 0.0082 & 0.513 \\
\hline
\end{tabular}

Table 2. XPS analysis of flax fibers after laccase treatment with different fluorophenols.

\begin{tabular}{cccccc}
\hline Sample & \% C & \% F & \% O & F/C & O/C \\
\hline Flax + Laccase & 76.8 & - & 20.6 & 0 & 0.268 \\
Flax + Laccase + 4,2-FMP & 76.1 & - & 20.3 & 0 & 0.267 \\
Flax + Laccase + 4,-F3MP & 70.4 & 4.7 & 22.1 & 0.067 & 0.314 \\
Flax + Laccase + 4,4-F3MPP & 72.8 & 0.3 & 24.3 & 0.004 & 0.334 \\
\hline
\end{tabular}

The results indicated a similar trend regarding the reactivity of the different fluorophenols for both fibers. The 4-F3MP was the most reactive since it was grafted to the highest extend, followed by 4,4-F3MPP, whereas 4,2-FMP did not attach neither to flax nor to coconut fibers. The latter result can 
be attributed to the fact 4,2-FMP is a laccase substrate and intramolecular polymerization reaction in solution were most predominant [16]. Similarly Kudanga et al. [16] reported a lower reactivity in the case of 4,2-FMP, whereas they observed a higher amount of fluorophenol content for 4,4-F3MPP vs. 4-F3MP using as substrate beech veneers. The different content and distribution of lignin in the fibers compared with the beech veneers may also be the reason for the reactivity difference. Using different phenols, Schroeder et al. [26] showed that different phenols were grafted to different extents on flax as evidenced by color properties and antibacterial activities.

Although the results obtain for both fibers are promising they clearly flax fibers were more amenable to laccase mediated modification and consequently the further experiments were conducted with this material.

Amine based functional molecules were also grafted onto the flax fibers. This is based on the fact that laccase or laccase/mediator oxidized phenolic molecules can also be used to create cation radicals, that could then react with electron donating species like amines via either Michael addition [27] or radical coupling [28] as shown in Figure 2, leading to new $\mathrm{C}-\mathrm{N}$ bonds and similar products [17].

Figure 2. Reaction mechanism for the coupling of amines to phenolic radicals [17]:

(a) Michael addition to quinine; and (b) Radical coupling to form new $\mathrm{C}-\mathrm{N}$ bond.
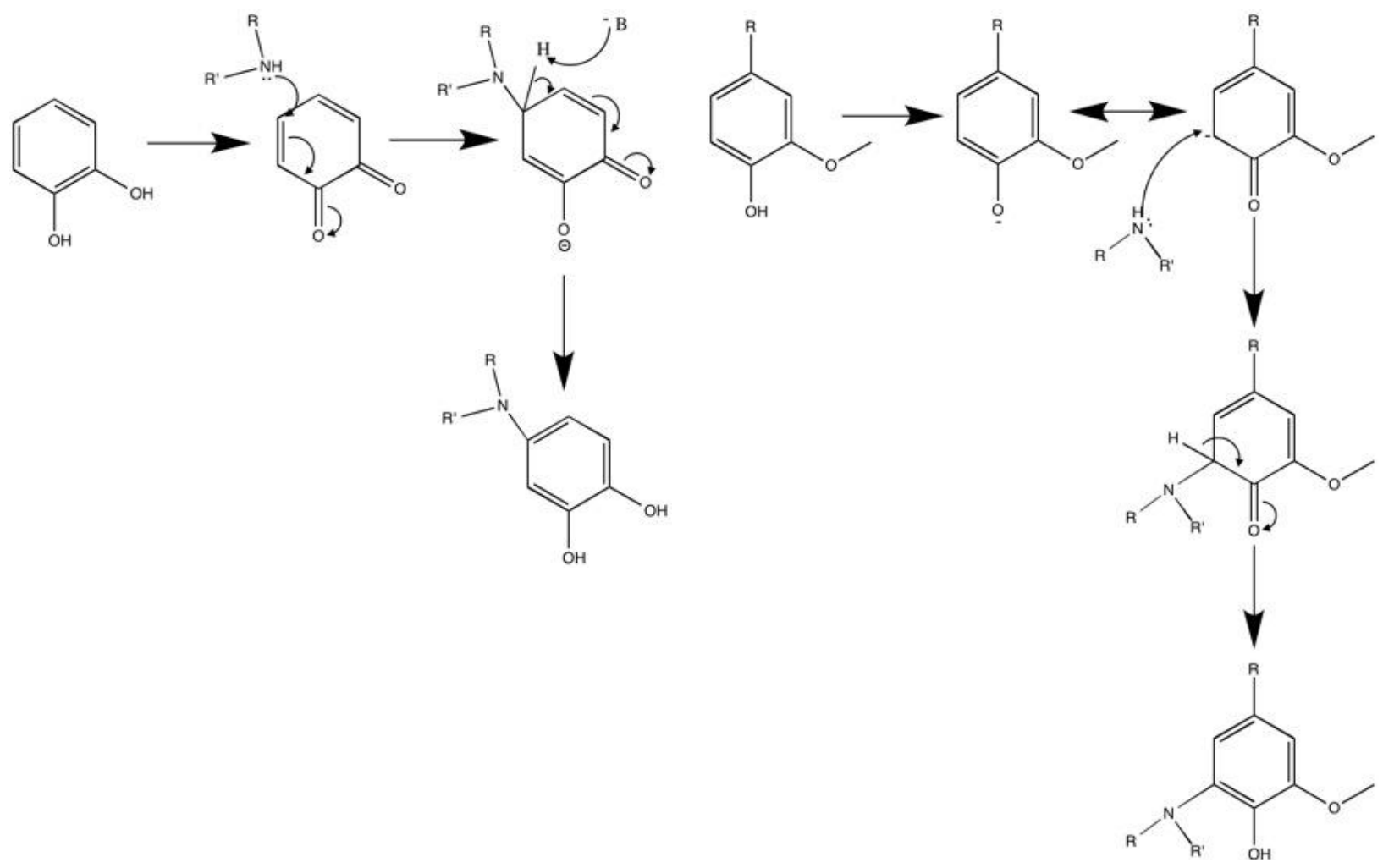

(a)

(b)

In order to widen the substrate specificity and achieve a more efficient binding, three different mediators namely HBT, ABTS and TEMPO were also included in the experiment. Mediators are small molecules that act as electron shuttles between the laccase and the substrate broadening the oxidation range. In the particular case of flax fibers, the most effective mediator was TEMPO, which was able to clearly catalyse grafting of DFA onto flax fibers as shown by the significant increase of the total 
amount of carbon, as well as the nitrogen content (Table 3). HBT and ABTS did not increase significantly the amount of bound DFA to the flax. In a similar fashion, tyrosyl silk residues were also successfully oxidized to their corresponding o-quinone, and subsequently reacted with amino groups of chitosan [29]. In addition, the peak position assigned to the aliphatic $\mathrm{C}$ (peak at $284.8 \mathrm{eV}$ ) increased its content from the $29.5 \%$ in the case of the sample treated with laccase and DFA compared with the $54.4 \%$ of the TEMPO treated sample (Table 3 ).

Table 3. XPS analysis of flax fibers after laccase treatment with dimer fatty amines (DFA).

\begin{tabular}{cccc}
\hline Sample & \% C & \% N & \% O \\
\hline Flax + Laccase & 72.5 & 3.9 & 23.3 \\
Flax + Laccase + DFA & 70.5 & 4.2 & 25 \\
Flax + Laccase + DFA+HBT & 73.7 & 4.4 & 21.5 \\
Flax + Laccase + DFA+ABTS & 71.9 & 4.5 & 23.3 \\
Flax + Laccase + DFA+TEMPO & 80.3 & 5.8 & 13.6 \\
\hline
\end{tabular}

In addition, the peak position at $400.0 \mathrm{eV}$, assigned to the $\mathrm{C}-\mathrm{N}$ bond also increased from $3.2 \%$ in the case of the blank with laccase and DFA to $4.9 \%$ for the TEMPO mediated reaction.

The mediators tested have different reaction mechanisms HBT and TEMPO oxidize via the generation of $\mathrm{N}-\mathrm{O}^{*}$ radicals while ABTS oxidizes via cation $\mathrm{ABTS}^{+}$radical (Figure 3 ). In agreement with previous results $\mathrm{N}$-heterocycles and mediators carrying $\mathrm{N}-\mathrm{OH}$ were more effective [30] while addition TEMPO lead the highest functionalization level.

Figure 3. Chemical structures of the mediators used.
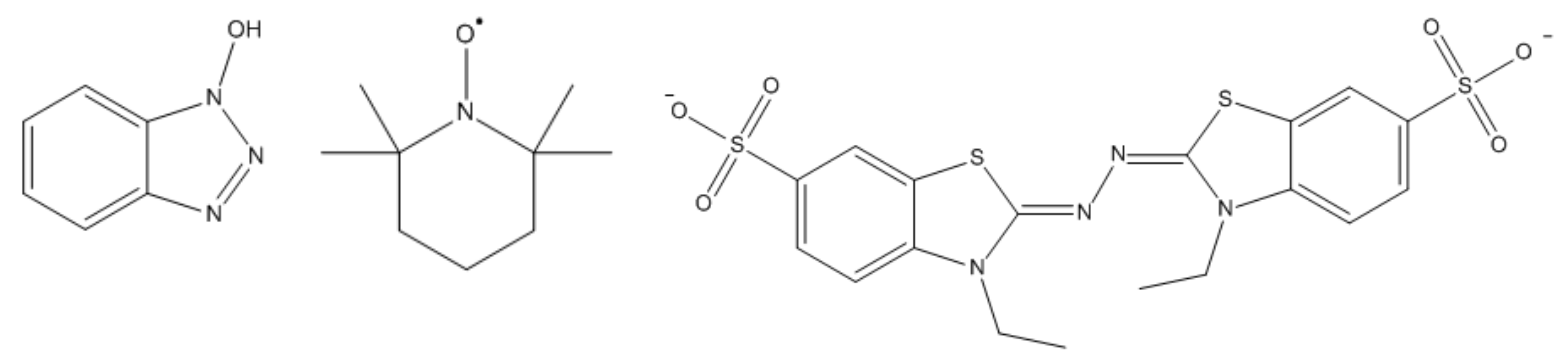

The enzymatic coupling of hydrophobic molecules to natural fibers has substantial benefits when the fibers are used as reinforcement in polymer composites. The adhesion between the fiber and the polymer matrix is improved, leading to increases in the tensile strength and tensile modulus of the composite [31]. Interestingly from both $\mathrm{N}-\mathrm{OH}$ mediators the most effective one was TEMPO. Natural materials typically have a great many functional groups, which when combined with a carefully selected right enzyme can turn be effectively be used in modifying polymer properties. Oxidative polymer activation for further functionalization has been successfully applied in the construction of biopolymer conjugates of chitosan and green fluorescence protein [32].

As shown in this study, this oxidative functionalization requires an activation step in which reactive groups are generated on the polymer surface or the functional molecule. For example polypropylene was treated with plasma to insert different methacrylate monomers to graft guaicaol sulfonic acid with a laccase in a subsequent step [26]. Hydrolytic enzymes have been also used for the to partially hydrolyze the surface of polyamide, generating free groups reactive groups in which phenols were 
coupled in a similar fashion as described in this publication [33]. Nevertheless, when in the polymer structure there are appropriate reactive groups, direct laccase grafting of phenolics is also possible [34].

\section{Conclusions}

In this paper, we have clearly demonstrated the viability of using laccases as effective environmentally friendly catalyst to mediate the direct grafting of different phenols and amines on coconut and flax fibers. The different phenols showed distinctive reactivity and can be used as carriers of the different chemical moieties that could increase the compatibility with the desire polymer. Using mediators is possible to enlarge the substrate scope and effectively graft a hydrophobic molecule to improve the hydrophobicity of the fiber.

\section{Acknowledgments}

This work has been supported by the Federal Ministry of Science, Research and Economy (BMWFW), the Federal Ministry of Traffic, Innovation and Technology (bmvit), the Styrian Business Promotion Agency (SFG), the Standortagentur Tirol and Technology Agency of the City of Vienna (ZIT) through the Competence Centers for Excellent Technologies (COMET) Funding Program managed by the Austrian Research Promotion Agency (FFG).

\section{Conflicts of Interest}

The authors declare no conflict of interest.

\section{References}

1. Kudanga, T.; Burton, S.; Nyanhongo, G.S.; Guebitz, G.M. Versatility of oxidoreductases in the remediation of environmental pollutants. Front. Biosci. 2012, 4, 1127-1149.

2. Yaropolov, A.I.; Skorobogatko, O.V.; Vartanov, S.S.; Varfolomeyev, S.D. Laccase properties, catalytic mechanism, and applicability. Appl. Biochem. Biotechnol. 1994, 49, 257-280.

3. Burton, S.G. Laccases and phenol oxidase in organic synthesis-A review. Curr. Org. Chem. 2003, 7, 1317-1331.

4. Mikolasch, A.; Niedermeyer, T.H.J.; Lalk, M.; Hammer, E.; Seefeldt, S.; Hammer, E. Novel penicillins synthesized by biotransformation using laccase from Trametes spec. Chem. Pharm. Bull. 2006, 54, 632-638.

5. Agematu, H.; Tsuchida, T.; Kominato, K.; Shibamoto, N.; Yoshioka, T.; Nishida, H.; Okamoto, R.; Shin, T.; Murao, S. Enzymatic dimerization of penicillin X. J. Antibiot. 1993, 46, 141-148.

6. Zamorani, A.; Spettoli, P.; Lante, A.; Crapisi, A.; Pasini, G. Immobilized laccase and tyrosinase: An approach for wine stabilization. Ital. J. food Sci. 1993, 4, 409-414.

7. Cantarelli, C.; Giovanelli, G. White wine stabilization treatments by enzymatic oxidation of polyphenols. Rev. Fr. Oenol. 1990, 127, 15-25.

8. Almansa, E.; Kandelbauer, A.; Pereira, L.; Cavaco, P.; Guebitz, G.M. Influence of structure on dyedegradation with laccase mediator systems. Biocatal. Biotransform. 2004, 22, 315-324. 
9. Abadulla, E.; Robra, K.H.; Gubitz, G.; Silva, L.; Cavaco-Paulo, A. Enzymatic decolorization of textile dyeing effluents. Text. Res. J. 2000, 70, 409-414.

10. Bourbonnais, R.; Paice, M.G. Demethylation and delignification of kraft pulp by Trametes versicolor laccase in the presence of 2,2-azinobis-(3-ethylbenzthiazoline-6-sulphonate). Appl. Microbiol. Biotechnol. 1992, 36, 823-827.

11. Camarero, S.; Garcia, O.; Vidal, T.; Colom, J.; del Rio, J.C.; Gutierrez, A.; Gras, J.M.; Monje, R.; Martinez, M.J.; Martinez, A.T. Efficient bleaching of non-wood high-quality paper pulp using laccase-mediator system. Enzyme Microbiol. Technol. 2004, 35, 113-120.

12. Aracri, E.; Fillat, A.; Colom, J.F.; Gutiérrez, A.; del Río, J.C.; Martínez, Á.T.; Vidal, T. Enzymatic grafting of simple phenols on flax and sisal pulp fibres using laccases. Bioresour. Technol. 2010, 101, 8211-8216.

13. Chandra, R.P.; Ragauskas, A.J. Evaluating laccase-facilitated coupling of phenolic acids to high-yield kraft pulps. Enzyme Microb. Technol. 2002, 30, 855-861.

14. Elegir, G.; Kindl, A.; Sadocco, P.; Orlandi, M. Development of antimicrobial cellulose packaging through laccase-mediated grafting of phenolic compounds. Enzyme Microb. Technol. 2007, 43, 3-37.

15. Barzyk, D.; Page, D.; Ragauskas, A.J. Acidic group topochemistry and fiber-to-fiber specific bond strength. J. Pulp Pap. Sci. 1997, 23, 59-61.

16. Kudanga, T.; Prasetyo, E.N.; Widsten, P.; Kandelbauer, A.; Jury, S.; Heathcote, C.; Sipila, J.; Weber, H.; Nyanhongo, G.S.; Guebitz, G.M. Laccase catalyzed covalent coupling of fluorophenols increases lignocellulose surface hydrophobicity. Bioresour. Technol. 2010, 101, 2793-2799.

17. Kudanga, T.; Prasetyo, E.N.; Sipila, J.; Guebitz, G.M.; Nyanhongo, G.S. Reactivity of long chain alkylamines to lignin moieties: Implications on hydrophobicity of lignocellulose materials. J. Biotechnol. 2010, 149, 81-87.

18. Nabi Saheb, D.; Pog, J.P. Natural fiber polymer composites: A review. Adv. Polym. Technol. 1999, 18, 351-363.

19. Greimel, K.J.; Perz, V.; Koren, K.; Feola, R.; Temel, A.; Sohar, C.; Herrero Acero, E.; Klimant, I.; Guebitz, G.M. Banning toxic heavy-metal catalysts from paints: Enzymatic cross-linking of alkyd resins. Green Chem. 2013, 15, 381-388.

20. Nyanhongo, G.S.; Nugroho Prasetyo, E.; Herrero Acero, E.; Guebitz, G.M. Engineering strategies for successful development of functional polymers using oxidative enzymes. Chem. Eng. Technol. 2012, 35, 1359-1372.

21. Kudanga, T.; Prasetyo, E.N.; Sipila, J.; Nyanhongo, G.S.; Guebitz, G.M. Enzymatic grafting of functional molecules to the lignin model dibenzodioxocin and lignocellulose material. Enzyme Microb. Technol. 2010, 46, 272-280.

22. Schultz, A.; Jonas, U.; Hammer, E.; Schauer, F. Dehalogenation of chlorinated hydroxybiphenyls by fungal laccase. Appl. Environ. Microbiol. 2001, 67, 4377-4381.

23. Jonas, U.; Hammer, E.; Haupt, E.T.K.; Schauer, F. Characterisation of coupling products formed by biotransformation of biphenyl and diphenyl ether by the white rot fungus Pycnoporus cinnabarinus. Arch. Microbiol. 2000, 174, 393-398.

24. Božič, M.; Gorgieva, S.; Kokol, V. Laccase-mediated functionalization of chitosan by caffeic and galic acids for modulating antioxidant and antimicrobial properties. Carbohydr. Polym. 2012, 87, 2388-2398. 
25. Barneto, A.G.; Aracri, E.; Andreu, G.; Vidal, T. Investigating the structure-effect relationships of various natural phenols used as laccase mediators in the biobleaching of kenaf and sisal pulps. Bioresour. Technol. 2012, 112, 327-335.

26. Schroeder, M.; Fatarella, E.; Kovac, J.; Guebitz, G.M.; Kokol, V. Laccase-induced grafting on plasma-preatreated polypropylene. Biomacromolecules 2008, 9, 2735-2741.

27. Witayakran, S.; Ragauskas, A.J. Modification of high-lignin softwood kraft pulp with laccase and amino acids. Enzyme Microb. Technol. 2009, 44, 176-181.

28. Niedermeyer, T.H.J.; Mikolasch, A.; Lalk, M. Nuclear amination catalyzed by fungal laccases: Reaction products of $p$-hydroquinones and primary aromatic amines. J. Org. Chem. 2005, 70, 2002-2008.

29. Sampaio, S.; Taddei, P.; Monti, P.; Buchert, J.; Freddi, G. Enzymatic grafting of chitosan onto Bombyx mori silk fibroin: Kinetic and IR vibrational studies. J. Biotechnol. 2005, 116, 21-33.

30. Riva, S. Laccases: Blue enzymes for green chemistry. Trends Biotechnol. 2006, 24, 219-226.

31. Cantero, G.; Arbelaiz, A.; Llano-Ponte, R.; Mondragon, I. Effects of fibre treatment on wettability and mechanical behavior of flax/polypropylene composites. Compos. Sci. Technol. 2003, 63, 1247-1254.

32. Chen, T.H.; Small, D.A.; Wu, L.Q.; Rubloff, G.W.; Ghodssi, R.; Vazquez-Duhalt, R.; Bentley, W.E.; Payne, G.F. Nature-inspired creation of protein-polysaccharide conjugate and its subsequent assembly onto a patterned surface. Langmuir 2003, 19, 9382-9386.

33. Acero, E.H.; Ribitsch, D.; Rodriguez, R.D.; Dellacher, A.; Zitzenbacher, S.; Marold, A.; Greimel, K.J.; Schroeder, M.; Kandelbaueret, A.; Heumann, S.; et al. Two-step enzymatic functionalisation of polyamide with phenolics. J. Mol. Catal. Enzym. 2012, 79, 54-60.

34. Nady, N.; Schroën, K.; Franssen, M.C.; Lagen, B.V.; Murali, S.; Boom, R.M.; Mohyeldin, M.S.; Zuilhof, H. Mild and highly flexible enzyme-catalyzed modification of poly(ethersulfone) membranes. ACS Appl. Mater. Interfaces 2011, 3, 801-810.

(C) 2014 by the authors; licensee MDPI, Basel, Switzerland. This article is an open access article distributed under the terms and conditions of the Creative Commons Attribution license (http://creativecommons.org/licenses/by/3.0/). 